* Mestre em Direito Negocial pela Universidade Estadual de Londrina; Professor do Curso de Gradu-ação em Direito da Universidade Norte do Paraná e do Curso de Pós-graduação Lato Sensu em Direito Empresarial da Universidade Estadual de Londrina e Procurador da Fazenda $\mathrm{Na}$ cional em Londrina. E-mail: alessandrolucas@yahoo.com

** Mestre e Doutora em Direito pela Pontifícia Universidade Católica de São Paulo; Professora dos Cursos de Graduação, Especialização Lato Sensu e Mestrado em Direito Negocial da Universidade Estadual de Londrina, professora dos Cursos de Graduação e Mestrado em Direito da Universidade de Marília e professora do Curso de Graduação em Direito da Pontifícia Universidade Católica do Paraná. E-mail: mkempferb@gmail.com

\section{Estado contemporâneo e intervenção no domínio econômico}

\section{CONTEMPORARY STATE AND INTERVENTION IN THE ECONOMIC DOMAIN}

\author{
Alessandro Lucas Santos * \\ Marlene Kempfer **
}

Resumo: Sob uma perspectiva semântico-pragmática, este artigo estipula uma definição jurídico-positiva de "intervenção do Estado sobre o domínio econômico" como a atuação do Estado sobre atividades econômicas em sentido estrito, no campo de titularidade da iniciativa privada, como também sobre os serviços públicos não essenciais, chamados impróprios. Essa intervenção do Estado pode ocorrer por participação direta (art. $173, \mathrm{CF} / 88$ ) ou na condição de agente normativo e regulador (art. 174, CF/88), exercendo as funções de fiscalização, incentivo e planejamento.

Palavras-chave: Intervenção do Estado no Domínio Econômico; Dimensão Semântico-Pragmática; Classificação da Intervenção Estatal.

Abstract: From a semantic-pragmatic perspective, this article stipulate a positive-legal definition of "state intervention on the economic domain" as state action on economic activities in the strict sense, related to the private initiative, as well as on nonessential public services, called improper. This state intervention can occur by direct participation (art. 173, CF/88) or acting as normative and regulating agent (art. 174, CF/88), performing the oversight, planning and incentive functions.

Key-words: State Intervention on the Economic Domain; Semantic-Pragmatic Dimension; Classification of State Intervention. 


\section{INTRODUÇÃO}

As ideologias próprias de cada povo, num dado momento histórico, são manifestadas nas opções políticas acerca das atribuições do Estado, inclusive no que tange ao tamanho e às formas da ingerência estatal na órbita econômica.

$\mathrm{Na}$ monarquia absolutista, a violência física e a tributação eram monopólios pessoais do rei. Com a Revolução Francesa e o surgimento do Estado Moderno, o Estado-burguês, esses dois monopólios pessoais do soberano transformaram-se em monopólios públicos, no sentido de terem sido transferidos ao controle institucional da burguesia.

O Estado Moderno, que inicialmente exerceu as atribuições de defensor da propriedade (ordem e tranqüilidade públicas), da liberdade e do modo de produção capitalista, na passagem do século XIX para o século $\mathrm{XX}$, recebeu as funções contemporâneas de substituição e compensação do mercado. Esses novos papéis do Estado foram-lhe conferidos para o enfrentamento das mazelas sociais e econômicas provocadas pelo liberalismo, ou seja, pela incapacidade de o mercado se auto regular, o surgimento de monopólios e o exacerbado conflito entre capital e trabalho, com a hegemonia do primeiro.

A ação pública é condição do desenvolvimento econômico, considerando que há uma flagrante conexão entre a tendência à acumulação de capital e a extensão das funções estatais. Justamente nesse contexto, no presente artigo, tratará inicialmente das relações entre Estado, direito, economia e desenvolvimento, abordando as ideologias das antagônicas posições sobre o "quanto de Estado" (Estado Liberal e Estado-social).

Posteriormente, adentrando a realidade jurídica do Estado contemporâneo brasileiro, buscará investigar, a partir da ordem econômica enquanto "mundo do dever-ser", a amplitude semântico-pragmática da expressão "intervenção do Estado no domínio econômico".

Ainda promoverá, ao final, o estudo das formas de intervenção participativa e normativa do Estado no domínio econômico, as quais foram contempladas no texto da Constituição Federal de 1988 como instrumentos de incentivo e proteção do mercado interno, com o objetivo de promover o desenvolvimento cultural e sócio-econômico, o bem-estar da população e a autonomia tecnológica do País, nos termos do artigo 219 da Lei Maior. 


\section{ESTADO CONTEMPORÂNEO: "QUANTO DE ESTADO"}

A natureza do direito é instrumental, pois ele consiste num meio especial, dotado da coatividade imposta pelo Estado, de se atingir certas finalidades, visando assegurar valores consagrados por um povo num dado contexto histórico-social. $\mathrm{O}$ dado instrumental e o elemento valorativo estão presentes em toda configuração do jurídico.

É o direito, também, uma força social, na medida em que direciona, acelera ou retarda as mudanças da sociedade. Como objeto cultural, provém da realidade social e sobre esta se volta para regular, sendo uma questão de política do direito a de editar normas para inserir no ordenamento jurídico o dado social extra-sistemático, até então ignorado pela metalinguagem prescritiva, visando o atingimento de finalidades. Na lição de Marcelo Neves (1994, p.20):

[...] a vigência das expectativas normativas não é determinada imediatamente por interesses econômicos, critérios políticos, representações éticas, nem mesmo por proposições científicas, ela depende de processos seletivos de filtragem no interior do sistema jurídico.

No contexto histórico atual, é preciso frisar, o desenvolvimento sócioeconômico é um dos grandes fins perseguidos pelo Estado-de-direito. Diz-se que o Estado é o poder social institucionalizado pelo direito. Nas palavras de Lourival Vilanova (2003, p.463-498), esse poder assume a empresa do desenvolvimento racionalizado. "O direito tanto sobre a mudança, a passagem do subdesenvolvimento para o desenvolvimento, como por sua vez opera como fator, detendo ou promovendo a mudança.", ensina o jusfilósofo pernambucano.

Muito embora o direito, como sistema normativo, seja um fator que retarda ou acelera o desenvolvimento, partindo-se de uma visão constructivista, não se pode confundir a realidade econômica com a realidade jurídica. Isso implica em indagar como o direito opera sobre o meio.

A rigor, mundo do "ser" e mundo do "dever-ser" tratam-se de sistemas de comunicação autônomos, dois "jogos de linguagem", pois, como observa Paulo de Barros Carvalho (1995, p.83), há, necessariamente, um intervalo entre a realidade social (constituída pela linguagem natural) e a realidade jurídica (constituída pela linguagem prescritiva do direito). O direito atua, sim, sobre o meio, mas o faz pela via da prescrição de condutas humanas, jamais produzindo, diretamente, realidade econômica. 
Acata-se, neste ponto, o pensamento de Tácio Lacerda Gama (2003, p.237), para quem "O direito percebe as demandas da realidade econômica, porém sua única forma de atuar é por meio da produção de mais direito normas - nunca por meio da produção de realidade econômica." Com sua peculiar precisão, no mesmo excerto, arremata dizendo: "Não é porque existem normas prescrevendo a prosperidade da nação que ela será necessariamente próspera, pois a tarefa de produzir riqueza é do sistema econômico e não do jurídico."

Nessa mesma linha constructivista, Gunther Teubner (1993, p.160) assinala:

[...] de um ponto de vista constructivista, as intervenções do direito na economia devem ser entendidas como observações recíprocas entre dois sistemas de comunicação hermeticamente fechados e autônomos. O direito "inventa" uma imagem da economia, formulando as respectivas normas em referência a tal imagem. A economia inventa uma imagem do "direito", processando os atos de pagamento também como referência a esta. E embora estes modelos imaginários intra-sistêmicos do mundo exterior possam ser continuamente refinados, como acontece com a moderna escola de análise econômica do direito, a verdade é que isso jamais conduzirá das concepções jurídicas do sistema econômico à realidade do próprio sistema econômico.

Colocados os termos em que se entende a ocorrência de intervenção do direito sobre a realidade econômica, pondera que o "quanto de Estado" será uma opção política da sociedade, tendente a dosar as porções de mercado e de Estado segundo valores ou ideologias próprias de cada povo, ao longo de sua trajetória histórica (NUSDEO, 2005, p.211).

O Estado-liberal do século XVIII, sob o ideário da Revolução Francesa, preconizava um reduzido papel estatal na busca do progresso econômico, que seria alcançado pela salvaguarda das liberdades individuais, garantindo a ordem pública e as boas condições de competição entre os particulares. Assim, o liberalismo pôs a tônica do progresso nas liberdades individuais e no Poder Legislativo, que representava a vontade geral, em antagonismo ao Estado Absolutista, mitigando sobremaneira a intervenção do Estado na economia.

No pensamento liberal clássico, o "quanto de Estado" vai ao mínimo, pois a "mão invisível", de que falou Adam Smith em "A Riqueza das Nações", regularia o mercado (HUGON, 1995, p.106). Sobre o laissez-faire, laissez- 
passer, regra de ouro do pensamento liberal clássico, leciona Manoel Gonçalves Ferreira Filho (1990, p.3):

Tal omissão ajusta-se, ademais, perfeitamente ao pensamento econômico liberal, segundo o qual a regra de ouro seria o laissez-faire, laissez-passer, devendo o Estado abster-se de ingerência na órbita econômica. Melhor do que ele, mais sabiamente do que ele, a 'mão invisível' de que fala Adam Smith regularia a economia. [...] Inspira-se o ideário econômico que Adam Smith tão bem exprimiu no famoso livro A Riqueza das Nações. Ou seja, que a satisfação das necessidades gerais da comunidade melhor se dá pela livre concorrência entre homens que, perseguindo diretamente interesses egoísticos (o próprio lucro), logram o interesse geral, sem dele cogitarem, guiados por uma como que 'mão invisível'. E isto em face de um Estado que não intervém no plano econômico, zelando apenas pela manutenção da ordem pública e das demais condições da competição.

Os desequilíbrios na produção e no consumo, os abusos do poder econômico e as distorções sociais daí naturalmente advindas, tudo decorrente da complexidade da economia moderna, geraram preocupações econômicas que adentraram os textos constitucionais, redimensionando o "quanto de Estado". Cita-se, em exemplário, a Constituição mexicana de 1917, a Lei Fundamental soviética de 1918 e a Constituição alemã de 1919 (a Constituição de Weimar), com seu destacado capítulo sobre a Vida Econômica.

Como anota Lourival Vilanova (2003, p.463-498), o Estado-liberal dá lugar ao Estado-social-de-direito; a ideologia clássico-liberal do progresso cede ao ideal de desenvolvimento; e o mínimo de Estado vai ao máximo, quer com a manutenção de estruturas democráticas e das liberdades individuais (bem-estarsocial), quer com a total estatização da economia (Estado Social).

Na superação do liberalismo, a análise da expansão estatal permite a constatação de uma dicotomia (DANTAS, 2002, p.38): enquanto no Estadoliberal há prevalência do Poder Legislativo e as liberdades individuais juridicamente consagradas implicam num "não-fazer" do Estado; no Estadosocial, a expansão estatal implica no grande fortalecimento do Poder Executivo, sendo que os direitos sociais relevam um plexo de atividades positivas, um "fazer" do Estado-prestador.

Sobre o comentado reforço do Poder Executivo, Lourival Vilanova (2003, p.463-498) esclarece que se trata de um fenômeno geral, próprio das sociedades em mutação, pois a intervenção do Estado na economia, muitas vezes, exige 
juízo discricionário, conhecimentos técnicos altamente especializados, rapidez no processo de produção da regulação e sigilo na tomada das decisões (como sói ocorrer em matéria fiscal, cambial ou monetária), tudo que um órgão do Poder Legislativo não está apto a atender. Como consectário desse fortalecimento do Poder Executivo, segundo o autor, tem-se o fenômeno da deslegalização de matérias, com a ampliação do poder regulamentar.

Tratadas essas noções gerais sobre o "quanto de Estado", que se referem às duas antagônicas posições sobre a aceitação da presença estatal na economia, resta investigar em quais setores econômicos a atuação do Estado se faz mais necessária. Fábio Nusdeo sugere a análise de duas linhas de atuação estatal: (i) uma própria dos países desenvolvidos (Welfare State), em que o setor decisório público é de caráter distributivista; (ii) e outra, inerente aos países subdesenvolvidos ou em processo de desenvolvimento (Estado desenvolvimentista), de caráter preponderantemente produtivista.

Ao tratar da primeira dessas duas linhas de atuação estatal, inerente aos países desenvolvidos, Fábio Nusdeo (2005, p.216) ensina:

O Welfare State - Nas nações maduras, os Estados têm agido primordialmente no campo do bem-estar social, conhecido como Welfare State. Este nada mais vem a ser do que um conjunto de instituições cujo objetivo é assegurar ao conjunto de cidadãos um mínimo de atendimento às necessidades, particularmente no campo da saúde e saneamento, da edução e cultura, dos benefícios da seguridade social e, conseqüentemente, na orientação do aparelho produtivo à geração dos bens e serviços correspondentes. Integram o quadro institutos tais como o do seguro desemprego e os chamados programadas de renda mínima, onde se influi o conceito de imposto de renda negativo, ou seja, ao invés de pagar, aquele que recebe abaixo de um nível mínimo recebe uma compensação. Naturalmente todos esses programas são custeados por uma tributação diferenciada, a fim de captar os recursos de forma racional e sem gerar outros tipos de desigualdades ou distorções.

Mais adiante, a linha de atuação do Estado desenvolvimentista, própria das economias emergentes, foi assim identificada pelo referido autor (NUSDEO, 2005, p.217):

O Estado desenvolvimentista - Nos países de economia ainda por desenvolver, claramente, a ação estatal concentra-se nesse desiderato. São múltiplas e diversas tarefas neste campo $[\ldots]$ 
Como se vê, no chamado Primeiro Mundo, o setor decisório público é de cunho distributivista; no segundo, de cunho prevalentemente produtivista, isto é, voltado ao crescimento e à melhora da produção. Como assinalado, trata-se de duas linhas de ação estatal, não se entrando aqui na discussão dos setores onde ela possa se concentrar, o que levaria a uma discussão longa e estéril.

Quanto a este aspecto, assinale-se também que a ênfase produtivista tem repousado mais na direção - sob a forma de regulação do que na absorção. Ou seja tem havido uma maciça privatização de entes e empresas estatais, substituídas por mecanismos de acompanhamento e controle estatais tanto mais intensos e changentes quanto maiores as imperfeições dos mercados onde antes atuavam as empresas estatais. Para tanto tem-se dado grande ênfase às chamadas agências reguladoras independentes ou autônomas, como o são no Brasil a ANEEL, ANATEL, a ANP ou a ANA.

No final da década de 1980, o chamado consenso de Washington, de caráter neoliberalizante, coordenado pelos países altamente industrializados, colocou sob fogo cerrado o Welfare State, taxando-o de falido. O pensamento neoliberal prega que a intervenção estatal deve remover os obstáculos à livre iniciativa e à livre concorrência, garantindo o bom funcionamento do mercado e a estabilidade monetária (ANDERSON, 1995, p.10-11), redefinindo o papel do Estado com políticas de privatização e contenção de gastos com bem-estar (HUGON, 1995, p.153).

A essência do pensamento neoliberal continua sendo a liberdade utilitarista. Aceita a posição do Estado como corretor das inoperacionalidades de mercado, admitindo, também, seu papel de fomentador de desenvolvimento por meio de incentivos à iniciativa particular (NUSDEO, 2005, p.213). De acordo com Boaventura de Souza Santos (2002, p.43):

Nos termos do Consenso de Washington, a responsabilidade central do Estado consiste em criar o quadro legal e dar condições de efetivo funcionamento às instituições jurídicas e judiciais que tornarão possível o fluir rotineiro das infinitas interações entre os cidadãos, os agentes econômicos e o próprio Estado.

Discorrendo sobre o consenso de Washington, observa Fábio Nusdeo $(2005$, p.217) que "críticas mais recentes àquela tendência neoliberal tanto sob o aspecto teórico, quanto empírico - tem reabilitado, em parte, o ideário do Estado de bem-estar, de maneira que a questão está longe de ser resolvida 
[...].” Em consonância com tal observação, Eros Roberto Grau (2005, p. 57) entende que há contradição entre o neoliberalismo e a democracia, que pressupõe o amplo acesso das pessoas aos bens sociais. Ainda mais contunde ao realizar um balanço negativo do neoliberalismo, Perry Anderson (1995, p.23) conclui pelo seu fracasso econômico-social:

Economicamente, o neolliberalismo fracassou, não conseguindo nenhuma revitalização básica do capitalismo avançado. Socialmente, ao contrário, o neoliberalismo conseguiu muitos dos seus objetivos, criando sociedades marcadamente mais desiguais, embora não tão desestatizadas como queria. Política e ideologicamente, todavia, o neoliberalismo alcançou êxito num grau com o qual seus fundadores provavelmente jamais sonharam, disseminando a simples ideia de que não há alternativas para os seus princípios, que todos, seja confessando ou negando, têm de adaptar-se as suas normas.

Adentrando a realidade jurídica brasileira, a Constituição da República Federativa do Brasil, de 1988, adota um modelo dual ou misto, caracterizado por consagrar, ao lado do mercado e da salvaguarda da concorrência e livre iniciativa, um segundo centro decisório munido de diferenciadas ferramentas de intervenção estatal (direção, absorção e indução - artigos 170 a 174) para o atingimento de bem-estar social e proteção do mercado interno, enquanto elemento integrante do patrimônio nacional, sem, entretanto, provocar total centralização pela autoridade política. Neste aspecto, o artigo 219 da Constituição Federal preceitua:

Art. 219. O mercado interno integra o patrimônio nacional e será incentivado de modo a viabilizar o desenvolvimento cultural e sócio-econômico, o bemestar da população e a autonomia tecnológica do País, nos termos de lei federal.

Há, para Eros Roberto Grau (2005, p.47-48), marcante contradição ou incompatibilidade entre o pensamento neoliberal e o Estado de bem-estar consagrado no texto de 1988 , em especial nos preceitos contidos nos artigos $1^{\circ}$, $3^{\circ}$ e 170.

Os aspectos gerais sobre o "quanto de Estado", até aqui traçados, e tantos outros importantes que, por ora apenas por delimitação de objeto de investigação não se afigura pertinente debater, são indicativos da ampla ação 
estatal na economia e da juridicização do dado econômico, tanto pela via do ingresso no texto magno da Constituição, como por meio de extensa regulamentação normativa de inferior bitola. Prolixa, a atual Constituição contém dois títulos, um denominado "Da ordem econômico-financeira (VII); outro, "Da ordem social" (VIII), veiculando dezenas de artigos que se desdobram em tantos outros parágrafos e incisos, enunciando metalinguagem de relações econômicas.

\section{INTERVENÇÃO E DOMÍNIO ECONÔMICO: DIMENSÃO SEMÂNTICO-PRAGMÁTICA}

Tratar do tema da intervenção estatal na economia pressupõe, por imperativo lógico, abordar, numa tarefa deveras árdua, as significações de "intervenção", "domínio econômico" e "ordem econômica", os quais, sobre deterem fortes cargas de ambiguidade e vaguidade, não residem em solo doutrinário pacífico. No ponto, Eros Roberto Grau (2005, p.60) observa o seguinte: "a ambiguidade de todas essas expressões é de tal ordem - e uso aqui, propositadamente, o vocábulo ordem - que a operacionalização dos conceitos que designam é sempre tormentosa."

Intervir conota interferir, intrometer-se. Na visão de Estevão Horvath (2009, p.60), "Se se intervém é porque aquilo em que se vai intrometer não pertence, não é próprio daquele que pratica a intervenção, a 'introdução'.” E, mais adiante, no mesmo excerto, completa: "Destarte, quando se diz que o Estado intervém na atividade econômica é porque esta não lhe pertence como fim, ou pelo menos aquela determinada atividade econômica não se inclui entre as suas finalidades."

Esta percepção doutrinária do vocábulo "intervenção", ora emprestada, abre uma via especulativa para a diferenciação entre duas expressões incorporadas no discurso dos juristas: (i) "ação ou atuação do Estado"; e (ii) “intervenção do Estado". Não são expressões equivalentes. Enquanto a primeira indica as amplas formas de ação estatal, tanto no âmbito público como na esfera de titularidade alheia, a segunda indica unicamente a atuação do Estado no âmbito de outrem, na área de titularidade do setor privado, como diferencia Eros Roberto Grau (2001 apud HORVATH, 2009, p.60):

[...] intervenção indica, em sentido forte (isto é, na conotação mais vigorosa), no caso, atuação estatal em área de titularidade do setor privado; atuação

SCIENTIA IURIS, Londrina, v.16, n.2, p.175-198, dez.2012 
estatal, simplesmente, ação do Estado, tanto na área de titularidade própria quanto em área de titularidade do setor privado. Em outros termos, teremos que intervenção conota atuação estatal no campo da atividade econômica em sentido estrito; atuação estatal, ação do Estado no campo da atividade econômica em sentido amplo.

A atuação do Estado, como se depreende do exame dos artigos 173 e 175 da Constituição Federal, pode ocorrer em dois universos distintos, o dos serviços públicos e o da atividade econômica desenvolvida no âmbito do setor privado. Na terminologia empregada por Eros Roberto Grau (2005, p.103), tratase de dividir a ação estatal da seguinte forma: (i) atividade econômica em sentido amplo, que engloba, de um lado, a atividade econômica inerente ao âmbito privado e, de outro, os serviços públicos, já que estes existem para satisfazer necessidades e requerem a utilização de recursos escassos (sendo, pois, um tipo de atividade econômica); e (ii) atividade econômica em sentido estrito, no âmbito de titularidade do setor privado. Assim, o autor convenciona que "atividade econômica em sentido amplo" conota gênero, ao passo que "atividade econômica em sentido estrito", espécie.

Muito embora o texto da Constituição Federal de 1988 tenha separado, em dois campos distintos, a atividade econômica (artigo 173) e a prestação dos serviços públicos (artigo 175), o constituinte albergou ambos dispositivos no Capítulo I, do Título III, que regula os princípios da atividade econômica, em aparente contradição conceitual.

Com esta observação, percebe-se que a solução de classificação sugerida por Eros Roberto Grau, que toma a expressão "atividade econômica" em dois sentidos, uma como gênero e outra como espécie, é a única maneira plausível de se acatar a arquitetura do texto normativo maior, como enxerga Paulo Roberto Lyrio Pimenta. São suas palavras (PIMENTA, 2002, p.34):

[...] Como resolver essa aparente contradição, já que os arts. 173 e o 175 separam os campos reservados à iniciativa privada e pública, respectivamente, dizendo que se referem à atividade econômica e à prestação de serviço público? Vale dizer, o enunciado do art. 173 está para a atividade privada como o do art. 175 está para a pública.

Em nosso entendimento esse problema pode ser solucionado, como sugere Eros Roberto Grau, tomando a expressão atividade econômica em dois sentidos como gênero e como espécie. Como gênero, abrange duas espécies: o serviço público e a atividade econômica em sentido estrito. No art. 170 da 
CF a expressão aparece nesta acepção, alcançando, pois, os serviços públicos, eis que mencionados no art. 175. Já no art. 173 - que trata da intervenção direta - atividade econômica deve ser entendida em sentido estrito, significando a atuação estatal como agente econômico, realizando, desse modo, operações mercantis. De outro lado, no art. 174 (intervenção indireta) a expressão denota um sentido amplo.

A atividade econômica em sentido amplo, aí incluídos os serviços públicos, são o que parte da doutrina considera como sendo o conceito de "domínio econômico". Assim entende Tácio Lacerda Gama (2003, p.230), para quem, textualmente, "domínio econômico será entendido na sua acepção ampla, incluindo tanto o conjunto de atividades econômicas em sentido estrito, quanto os 'serviços públicos' prestados em regime de direito público.” E justifica: “A opção pelo sentido amplo permitirá um estudo mais detalhado das formas de atuação do Estado nas atividades econômicas."

Um dissenso doutrinário é avistado na posição mais restritiva adotada por Estevão Horvath. Amparando-se na lição de Eros Roberto Grau, que equipara domínio econômico a atividade econômica em sentido estrito, bem como na literalidade do artigo 173, da CF/88, que reserva o exercício direto de "atividade econômica" preferencialmente aos particulares, Estevão Horvath $(2009$, p.63) afirma categoricamente: "[...] reconhecemos que esta expressão [domínio econômico] se identifica com a atividade privada, ou aquela que a Constituição reservou para ser desempenhada, preferencialmente, pelos particulares."

Numa vertente intermediária, vale dizer, firmada entre o entendimento exposto por Tácio Lacerda Gama e aqueloutro advogado por Estevão Horvath, o professor e juiz federal na Bahia Paulo Roberto Lyrio Pimenta (2002, p.35), explica que "a expressão domínio econômico, mencionada no art. 149 da CF, pode denotar atividade econômica em sentido estrito, ou em sentido amplo. Em outros termos, domínio econômico não é sinônimo de atividade privada [...]". Entretanto, referido autor sustenta que somente os serviços públicos impróprios integram o conceito de domínio econômico, ressalva que faz com base no julgamento do Recurso Extraordinário $\mathrm{n}^{\mathrm{o}}$ 218.061, ocorrido em 2000, que examinou a natureza jurídica do Adicional de Tarifa Portuária.

Diante da falta de consenso da doutrina em torno do sentido da locução "domínio econômico", conclui-se que a ambiguidade e a multiplicidade do uso linguístico pelos juristas inviabilizam seja o termo tomado no sentido lexicográfico. Como o discurso da Ciência deve ser seguro a ponto de permitir a fiscalização 
de sua coerência, acata-se, neste trabalho, a sugestão dada por Tácio Lacerda Gama (2003, p.228), no sentido de se fixar uma definição estipulativa.

Assim, admite-se que o conteúdo semântico de "domínio econômico" engloba tanto as atividades econômicas em sentido estrito, de que falou Eros Roberto Grau, ou seja, o campo de titularidade da iniciativa privada, como os serviços públicos não essenciais, chamados “impróprios" pelos administrativistas. Nesse aspecto, Hely Lopes Meirelles (1996, p.298) emprega o critério da essencialidade do interesse atendido para classificar os serviços públicos em próprios ou impróprios.

Num primeiro momento, tal opção especulativa decorre da conclusão lógica de que somente se pode intervir sobre aquilo que não pertence ou não é próprio de quem pratica a intervenção. Neste sentir, "intervenção" e "domínio econômico" são empregados linguisticamente como termos que se confirmam mutuamente. Afinal, é incensurável concluir que "A ação de 'intervir' traz implícito o conceito de excepcionalidade, de atuação anormal, especial e temporária, de forma que ela só pode ocorrer onde a liberdade econômica do particular seja a regra." (SOUZA; GARCIA, 2001, p.82).

O Estado não pratica "intervenção no domínio econômico" quando presta serviços públicos essenciais sob o regime de direito púbico (ou normatiza ou fiscaliza tal prestação), já que aí se cogita do Estado operando no âmbito de titularidade própria, isto é, na esfera pública ou no "domínio público".

Por outro lado, é forçoso reconhecer a existência de serviços públicos referidos na Lei Maior que não são ínsitos ao Estado, não são essenciais, mas por serem de interesse público, foram a ele afetados "para serem explorados sob regime de direito público, diretamente por ele ou mediante concessão ou permissão, neste último caso, sendo remunerados por tarifa" (SOUZA; GARCIA, 2001, p.86). No presente recorte temático, tais serviços públicos não essenciais, como os relacionados à exploração dos portos, ao lado das atividades econômicas em sentido estrito, desempenhadas preferencialmente pelos particulares mediante livre iniciativa, integram o conteúdo semântico da locução "domínio econômico", consistindo campo passível de intervenção estatal.

Portanto, alinha-se o discurso desta pesquisa à lição de Marco Aurélio Greco (2001, p.14), que escreve:

Com efeito, não é todo campo da atividade (que apresente efeitos na economia) e que seja desenvolvida concretamente, que comporta intervenção por parte do Estado. 
Há, pelo menos, um campo de atividade em que não há espaço para intervenção. Trata-se da prestação de serviços públicos que estejam submetidos a regime de direito público.

[...] Para o fim do presente estudo, relevante é acentuar que, se determinada atividade configurar um serviço público, que se revista de caráter essencial à coletividade (sem aqui entrar nas várias concepções teóricas que podem ser assumidas neste tema), haverá um impedimento à existência de contribuição de intervenção. Não é todo campo abrangido pelo que se costuma denominar de "serviço público" que impede a existência de intervenção. Há partes desse amplo campo que, se forem exploradas em regime jurídico próprio da atividade econômica, podem admitir intervenção. A propósito, vide o debate instaurado no Supremo Tribunal Federal a propósito do Adicional de Tarifa Portuária (ATP).

Embora a noção de domínio econômico como área que extrapola os lindes da livre iniciativa e, assim, alcança certos serviços públicos, ainda que prestados sob o regime de direito público, seja uma definição estipulativa que afronta significativa parcela da doutrina tradicional, é certo que o alargamento da acepção de domínio econômico, numa evolução histórica, coaduna-se com a fisionomia do Estado Brasileiro Contemporâneo e com a realidade do momento histórico atual (SOUZA; GARCIA, 2001, p.89), caracterizada, dentre outros fatores, pela crise da dicotomia público/privada, descrita por Habermas como a privatização do Direito Público e publicização do Direito Privado (MARQUES NETO, 2002, p.178).

A ideia de intervenção estatal em atividade classificada como serviço público, que implica numa revolução do próprio conceito clássico de serviço público, vem sendo repetidamente admitida pelo Supremo Tribunal Federal, órgão judicante máximo que diz do direito em matéria constitucional. ${ }^{1}$

Deixando claro que não apenas o regime jurídico de direito público, mas também o conteúdo econômico da atividade (reveladora ou não de essencialidade) devem ser levados em conta para se admitir, ou não, a intervenção estatal e a imposição de CIDE, o Ministro do Supremo Tribunal Federal Ilmar Galvão assim enfrentou o tema (PIMENTA, 2002, p.34):

\footnotetext{
${ }^{1}$ Como se observa, em especial, quando da declaração de constitucionalidade da norma instituidora do Adicional de Tarifas Portuárias (ATP) havida no RE 209.365-3; quando da determinação da natureza da remuneração dos serviços públicos, no bojo do RE 89.976-RJ; e, enfim, por ocasião do julgamento do Adicional de Frete para Renovação da Marinha Mercante (AFRMM), de que tratou o RE 75.972, relatado pelo então Ministro Carlos Thopson Flores.
} 
[...] é certo que a exploração dos portos, no Brasil, constitui atividade afeta à União, que a pode realizar diretamente ou mediante autorização, concessão ou permissão (CF, art. 21, XII,f). Estaria, aí, configurada uma intervenção no domínio econômico, para fim de instituição da contribuição correspondente? Parece evidente que sim, visto não se estar diante de serviço público 'ínsito à soberania do Estado', ou prestação 'no interesse da comunidade' (RE n ${ }^{\circ}$ 89.876-RJ, Min. Moreira Alves). Aliás, nenhum dos serviços relacionados no inciso XII possui tais características. Não passam de atividades de natureza econômica que, por revestidas, isso sim, de interesse público, a Carta de 88 incumbiu à União, autorizando-a a explorá-las e não a prestá-las) diretamente ou por via de empresa privada.

Conclui-se, pois, que "domínio econômico" trata-se de conceito jurídicopositivo e não lógico-jurídico, porquanto seu conteúdo semântico, mutável, não é apriorístico e sim construído a posteriori, a partir do suporte físico da Constituição Federal (em especial do Título VII) e do contexto sócio-econômico vigente no país (isto é: texto e contexto). Como bem registrou o Ministro Nelson Jobim, ao proferir seu voto no julgamento que declarou a constitucionalidade do Adicional de Tarifa Portuária (RE 209.365-3): "Nada de metafísicas. História e política."

Esse modo de pensar o direito coaduna-se com os pressupostos do Constructivismo Lógico-Semântico, pois prestigia, em especial, o emprego da Semiótica e o estudo jurídico pelo Método Hermenêutico-Analítico (CARVALHO, 2009, p.215).

No jogo de linguagem chamado Direito, o cientista não deve se limitar a construções sintáticas ou a fórmulas lógicas com a pretensão de alcançar absoluta pureza ou coerência no discurso. Cabe a ele empreender investigação semântica da linguagem, realizando a análise dos conteúdos atribuídos aos símbolos positivados. É no plano semântico que se enfrenta as mazelas da linguagem vaga e ambígua do legislador, como se viu na árdua tarefa de atribuir sentido à expressão "intervenção do Estado no domínio econômico", enunciada no artigo $149 \mathrm{da} \mathrm{CF} / 88$.

Já no campo da pragmática, investiga-se o modo como os indivíduos fazem uso da linguagem prescritiva do direito. Reside aí, justamente, a análise jurisprudencial do direito, bem como os temas afetos à edição e aplicação das normas jurídicas.

Sobre a importância do estudo do direito com o emprego da Semiótica (planos sintático, semântico e pragmático), assevera Sérgio Alves Gomes (2008, 
p. 2000) parecer "[...] não haver razões plausíveis para se duvidar da relevância do estudo do Direito mediante a perspectiva semiótica."

A atividade interpretativa de construção da mensagem prescritiva do direito encontra limites não apenas no plano de expressão textual, mas também nos horizontes culturais do intérprete e no contexto histórico-cultural, a revelar que os termos do direito, como "intervenção" domínio econômico", "serviços públicos" podem, e devem, ser constantemente reinterpretados, como preconiza o axioma interpretativo da inesgotabilidade, de que falou Paulo de Barros Carvalho (CARVALHO, 2009, p.215).

Como não há razões aceitáveis para se ignorar o plano pragmático da linguagem, na tríade semiótica do direito, a completude do fenômeno jurídico somente pode ser contemplada com a investigação jurisprudencial do uso linguístico do texto normativo, a revelar como os utentes dessa linguagem lidam com o deôntico, na orientação dos comportamentos intersubjetivos.

\section{CLASSFICIAÇÃO DAS FORMAS DE INTERVENÇÃO ESTATAL NO DOMÍNIO ECONÔMICO}

A classificação das diversas formas de intervenção do Estado no âmbito da economia é pertinente para se identificar os regimes jurídicos a que estão sujeitas tais modalidades da ação estatal.

Sobre o ato de classificar, importante instrumento de estudo do direito, Eurico de Santi (1988, p.132) leciona que "as classificações no direito positivo têm cunho nitidamente prescritivo e o fim perspícuo de outorgar regimes jurídicos e definir situações jurídicas específicas aos produtos dessas classificações."

Não há consenso na doutrina quanto à classificação das modalidades de intervenção do Estado no domínio econômico. Para Tácio Lacerda Gama (2003, p.237), é possível identificar duas grandes competências do Estado para influir no domínio econômico: ação normativa (edita normas e fiscaliza seu cumprimento) e ação participativa (atua como agente econômico). Como anota o mesmo autor, evidenciando as várias posições doutrinárias, Celso Antônio Bandeira de Melo adota classificação tripartida, em que descreve o Estado "disciplinando", "fomentando" ou "assumindo" a atividade econômica, mesmo entendimento seguido por Luis Roberto Barroso. Já Tércio Sampaio Ferraz Junior trata a "intervenção" como gênero, sendo espécies de atuação o "monopólio", a "regulação indireta" e a "organização direta". 
Eros Roberto Grau (2005, p.148-149), por sua vez, desenvolve classificação que distingue três modalidades de intervenção do Estado no domínio econômico: (i) intervenção por absorção ou participação; (ii) intervenção por direção; e (iii) intervenção por indução. No primeiro caso, o Estado desenvolve ação como agente econômico, operando na atividade econômica por absorção (monopólio) ou participação (regime de competição com empresas privadas). Na segunda hipótese, o Estado estabelece normas de comportamento compulsório para os agentes econômicos (sujeitos da atividade econômica em sentido estrito). E, na terceira, intervindo por indução, estabelece uma "sedução ao comportamento sugerido" (menor carga de cogência que caracteriza as normas dispositivas).

Classificação mais elaborada é sugerida por Paulo Roberto Lyrio Pimenta (2002, p.41-42), para quem a Lei Maior admite as modalidades de intervenção:

a) quanto ao critério do nível do envolvimento do Estado na atividade econômica: direta e indireta; b) quanto à técnica utilizada: intervençãoincentivo, intervenção-coação e intervenção-participação; c) quanto ao momento da intervenção: a priori (preventiva) e a posteriori (repressiva).

Nas seções seguintes, as diversas modalidades de intervenção do Estado no domínio econômico serão sistematizadas em dois grandes grupos, em virtude da natureza da ação interventiva: (i) intervenção como agente estatal participativo; e (ii) intervenção como agente estatal normativo e regulador.

\subsection{A Intervenção Participativa do Estado no Domínio Econômico}

A intervenção participativa do Estado no domínio econômico (expressão aqui adotada em sentido amplo, englobando o que Eros Roberto Grau (2005, p.148) dividiu em participação e absorção) está prevista, precipuamente, no artigo 173 da Constituição Federal, que estipula que, com a ressalva dos casos previstos pelo constituinte, "a exploração direta de atividade econômica pelo Estado só será permitida quando necessária aos imperativos da segurança nacional ou a relevante interesse coletivo, conforme definidos em lei."

Operando diretamente no domínio econômico (como agente econômico), o Estado ora atua em regime de concorrência com as empresas privadas, exercendo parcela dos meios de geração de riqueza, ora assume totalmente tais meios, em regime de monopólio (artigo 177, CF/88). Nas duas hipóteses, o 
Estado pratica atos típicos de direito privado, atuando como empresário, ou seja, produz, comercializa, importa, exporta e presta serviços privados, prevalecendo, por este motivo, o regime jurídico de direito privado.

Sobre essa modalidade de intervenção, Paulo Roberto Lyrio Pimenta (2002, p.39) escreve:

Nessa modalidade de intervenção (direta), em síntese apertada, o Estado, na qualidade de agente econômico da atividade produtiva não está submetido ao regime jurídico de direito público, por ser este incompatível com os fins e meios da ordem econômica. Assim, o Estado não goza de superioridade em suas relações com os particulares. Aqui, o ente estatal comercializa, importa, exporta, produz, enfim, pratica atos típicos de direito privado.

A participação estatal em sentido amplo, envolvendo a exploração direta monopolística (absorção) e a não monopolística (participação estatal em sentido estrito) são exercidas pelo Estado por meio da criação de empresas estatais: as empresas públicas, as sociedades de economia mista e suas subsidiárias. Neste aspecto, preceitua o $\S 1^{\circ}$, do artigo 173, da Constituição, com redação outorgada pela EC no 19/1998, que a lei estabelecerá “o estatuto jurídico da empresa pública, da sociedade de economia mista e de suas subsidiárias que explorem atividade econômica de produção ou comercialização de bens ou de prestação de serviços", devendo tal lei dispor, dentre outros temas, sobre sua sujeição ao regime jurídico de direito privado, próprio das empresas privadas, mas de outro lado, sobre a sua função social, formas de fiscalização pelo Estado, sujeição a licitação e aos princípios da Administração Pública, evidenciando o que Jürgen Habermas chamou de "publicização do direito privado" ou "privatização do direito público".

A justificativa para que o Estado possa explorar diretamente a atividade econômica em sentido estrito, como empresário, é dada pelo constituinte no artigo 173 da Lei Maior: "é o atendimento de situações consideradas por lei necessárias à manutenção da segurança nacional ou ao relevante interesse coletivo. Ressalvados esses casos, o Estado não poderá explorar diretamente a atividade econômica", explica Tácio Lacerda Gama (2003, p.243-244).

Adicionalmente, em decorrência da amplitude semântico-pragmática do conceito de "domínio econômico" que restou acatada no tópico anterior deste trabalho, com a observância dos repetidos pronunciamentos do Supremo Tribunal Federal (como no julgamento do ATP no RE 209.365-3), é forçoso reconhecer 
que, a par de sua operação como empresário, exercendo atividade econômica em sentido estrito sob o regime de direito privado, o Estado também participa no domínio econômico quando presta, por si ou quem lhe faça as vezes, diretamente ou mediante autorização, concessão ou permissão, os chamados serviços públicos impróprios (isto é, não essenciais), como aqueles previstos no artigo 21, inciso XII, do texto magno, listados abaixo:

a) os serviços de radiodifusão sonora, e de sons e imagens;

b) os serviços e instalações de energia elétrica e o aproveitamento energético dos cursos de água, em articulação com os Estados onde se situam os potenciais hidroenergéticos;

c) a navegação aérea, aeroespacial e a infra-estrutura aeroportuária;

d) os serviços de transporte ferroviário e aquaviário entre portos brasileiros e fronteiras nacionais, ou que transponham os limites de Estado ou Território; e) os serviços de transporte rodoviário interestadual e internacional de passageiros;

f) os portos marítimos, fluviais e lacustres;

De acordo com o enunciado contido no artigo 175, da Constituição Federal de 1988, "incumbe ao Poder Público, na forma da lei, diretamente ou sob regime de concessão ou permissão, sempre através de licitação, a prestação de serviços públicos." Aqui, sobre tratarem de serviços públicos, impera o regime de direito público, com prevalência do interesse público sobre o particular, conforme a clássica definição feita por Celso Antônio Bandeira de Mello (2002, p.600):

Serviço público é toda atividade de oferecimento de utilidade ou comodidade material destinada a satisfação da coletividade em geral, mas fruível singularmente pelos administrados, que o Estado assume como pertinentes aos seus deveres e que presta por si mesmo ou por quem lhe faça as vezes, sob regime de Direito Público - portanto consagrador de prerrogativas de supremacia e de restrições especiais -, instituídas em favor dos interesses definidos como públicos no sistema normativo.

Enfim, as explorações monopolística e concorrencial da atividade econômica em sentido estrito, sob regime de direito privado, e a prestação de serviços públicos impróprios, sob regime de direito público, são as duas formas de intervenção participativa do Estado no domínio econômico. De acordo com os pressupostos adotados neste capítulo, a prestação de serviços públicos próprios (essenciais e ínsitos à Soberania do Estado), por sua vez, trata-se da 
ação do Estado em campo que lhe é inerente, no domínio estritamente público, não se cogitando, aí, da figura da intervenção.

\subsection{A Intervenção Normativa do Estado no Domínio Econômico}

Além de participar da economia operando como agente do processo de geração de riquezas ou como prestador de serviços públicos impróprios, o Estado também intervêm no domínio econômico mediante atuação normativa, consistente na edição de normas jurídicas e na fiscalização do seu cumprimento.

Dispõe o artigo 174 da Constituição Federal de 1988, literalmente, que "Como agente normativo e regulador da atividade econômica, o Estado exercerá, na forma da lei, as funções de fiscalização, incentivo e planejamento, sendo este determinante para o setor público e indicativo para o setor privado." Rejeitase, nesta ocasião, a expressão "agente normativo e regulador", presente no texto da Constituição, haja vista sua evidente redundância.

Para Eros Roberto Grau (2005, p.149), enquanto no campo da ação participativa do Estado a intervenção dá-se "no" domínio econômico, na atuação normativa (direção ou indução), o Estado desempenha intervenção "sobre" o domínio econômico, por direção ou indução.

Quando o Estado intervém por direção, edita normas cogentes, vale dizer, comandos imperativos que exercem pressão sobre a economia, estabelecendo comportamentos compulsórios, como o tabelamento de preços. Trata-se da “intervenção-coação", assim descrita por Paulo Roberto Lyrio Pimenta (2002, p.41):

Outras vezes a atuação do Estado é para forçar, para coagir o indivíduo a praticar alguma conduta, ou para reprimir determinado ato considerado ofensivo de algum valor consagrado pelas finalidades constitucionalmente qualificadas. Em tais situações entendemos que existe a figura da intervençãocoação. Como exemplo desta modalidade tem-se o tabelamento de preços.

Mas, por outro lado, quando intervém por indução, o Estado estimula ou desestimula a prática de certos comportamentos, objetivando atingir uma finalidade consagrada na ordem econômica. Assim o faz editando normas indutoras de conduta, de impulsão. Trata-se da "intervenção-incentivo" (PIMENTA, 2002, p.40), cabendo esclarecer que tal indução tanto pode direcionar o agente econômico para um comportamento que representa a prática 
de um ato (p. ex., pela concessão de benefícios fiscais para o incremento de certas práticas), quando se fala em indução positiva, quanto para um comportamento que traduz a abstenção de uma prática (p. ex., pela elevação de certo tributo incidente na importação de bens do exterior), hipótese em que a indução é negativa (GRAU, 2005, p.150).

José Afonso da Silva (1992, p.686) enuncia que "incentivo, como função normativa e reguladora da atividade econômica pelo Estado, traz a ideia do Estado promotor da economia." Complementa dizendo que incentivo é "o velho fomento, conhecido dos nossos ancestrais, que consiste em proteger, estimular, promover, apoiar, favorecer e auxilar, sem empregar meios coativos [...].

No mais, resta dizer que a doutrina diverge quanto à classificação do planejamento como modalidade de intervenção estatal na economia. Na lição de Eros Roberto Grau (2005, p.151), "o planejamento, assim, não configura modalidade de intervenção [...] mas, simplesmente, um método a qualificá-la, por torná-la sistematizadamente racional."

Opinião diversa é defendida por Tácio Lacerda Gama (2003, p.238), para quem o planejamento é uma modalidade de intervenção normativa do Estado no domínio econômico. Nas suas palavras, o planejamento é uma espécie de fomento da atividade econômica que bem se ajusta ao conteúdo da competência estabelecida no artigo $174, \S 1^{\circ}$, da Lei Maior, que dispõe: "a lei estabelecerá as diretrizes e bases do planejamento do desenvolvimento nacional equilibrado, o qual incorporá e compatibilizará os planos nacionais e regionais de desenvolvimento."

Esse posicionamento firmado por Tácio Lacerda Gama está de acordo com o que ensina José Afonso da Silva (1992, p.686): “o planejamento econômico consiste, assim, num processo de intervenção estatal no domínio econômico com o fim de organizar atividades econômicas para obter resultados previamente colimados."

Observa-se, ainda, que essas modalidades de intervenção estatal no domínio econômico, sejam elas participativas ou normativas, são manifestações do poder soberano do Estado compartilhado nas esferas nacional, regional e local, no ambiente federativo da descentralização político-administrativa.

\section{CONCLUSÃO}

(i) O desenvolvimento sócio-econômico é um dos grandes fins perseguidos pelo Estado de Direito no Brasil. Nos termos do artigo 219, da CF/88, o mercado interno integra o patrimônio nacional e seu desenvolvimento deverá ser 
incentivado pelo Estado, nos termos de lei federal. O "quanto de Estado" será opção política da sociedade, segundo valores consagrados no texto da Constituição Federal, tendentes a dosar as porções de mercado e de Estado em conformidade com ideologias próprias de cada povo, ao longo de sua trajetória histórica.

(ii) A Constituição Federal de 1988 adotou um modelo dual ou misto, caracterizado por consagrar, ao lado do mercado e da salvaguarda da concorrência e livre iniciativa, um segundo centro decisório munido de diferenciadas ferramentas de intervenção estatal (direção, absorção e indução - artigos 170 a 174) para o atingimento de bem-estar social, sem, entretanto, provocar total centralização pela autoridade política.

(iii) Não há consenso da doutrina em torno do conteúdo semântico das expressões "Intervenção do Estado", "atuação do Estado" e "atividade econômica", de maneira que cabe ao jurista fixar definições estipulativas. As expressões "intervenção do Estado" e "atuação do Estado" não são equivalentes. Enquanto a primeira indica as amplas formas de ação estatal, tanto no âmbito público como na esfera de titularidade alheia, a segunda indica unicamente a atuação do estado no âmbito de outrem, na área de titularidade do setor privado. A expressão "atividade econômica em sentido amplo" conota gênero, enquanto "atividade econômica em sentido estrito", espécie. O sentido amplo engloba, de um lado, a atividade econômica inerente ao âmbito privado e, de outro, os serviços públicos, já que estes existem para satisfazer necessidades e requerem a utilização de recursos escassos (sendo, pois, um tipo de atividade econômica). Já o sentido estrito indica o âmbito de titularidade do setor privado.

(iv) Do mesmo modo, "domínio econômico" trata-se de conceito jurídicopositivo e não lógico-jurídico. Neste trabalho, levando-se em conta a jurisprudência do Supremo Tribunal Federal, admite-se que o conteúdo semânticopragmático de "domínio econômico" engloba tanto as atividades econômicas em sentido estrito, ou seja, o campo de titularidade da iniciativa privada, como os serviços públicos não essenciais, chamados "impróprios".

(v) O Estado está autorizado a promover intervenção participativa direta no domínio econômico, nas hipóteses enunciadas no artigo 173, da CF/88, nos termos de lei. Porém, o Estado também intervém no domínio econômico como agente normativo e regulador (art. 174, CF/88), exercendo as funções de fiscalização, incentivo e planejamento, por meio das quais deve buscar o atingimento dos objetivos da República (art. $3^{\circ}, \mathrm{CF} / 88$ ), prestigiando os princípios consagrados na Constituição. 


\section{REFERÊNCIAS}

ANDERSON, Perry. Balanço do neoliberalismo. Pós-neolliberalismo. São Paulo: Paz e Terra, 1995.

CARVALHO, Aurora Tomazini de. Curso de teoria geral do direito: o constructivismo lógico-semântico. São Paulo: Noeses, 2009.

CARVALHO, Paulo de Barros. Interpretação e linguagem - concessão e delegação de serviço público. Revista Trimestral de Direito Público. São Paulo: RT, n.10, 1995.

DANTAS, Ivo. Direito constitucional econômico - globalização \& constitucionalismo. Curitiba: Juruá, 2002.

FERREIRA FILHO, Manoel Gonçalves. Direito constitucional econômico. São Paulo: Saraiva, 1990.

GAMA, Tácio Lacerda. Contribuição de intervenção no domínio econômico. São Paulo: Quartier Latin, 2003.

GOMES, Sérgio Alves. Hermenêutica constitucional. Um contributo à construção do estado democrático de direito. Curitiba: Juruá Editora, 2008.

GRAU, Eros Roberto. A ordem econômica na constituição de 1988. 10.ed. São Paulo: Malheiros, 2005.

GRECO, Marco Aurélio. Contribuições de intervenção no domínio econômico - parâmetros para sua criação. In: GRECO, Marco Aurélio (Coord.). Contribuições de intervenção no domínio econômico e figuras afins. São Paulo: Dialética, 2001.

HORVATH, Estevão. Contribuições de intervenção no domínio econômico. São Paulo: Dialética, 2009. 
HUGON, Paul. História das doutrinas econômicas. 14 ed. São Paulo: Atlas, 1995.

MARQUES NETO, Floriano Peixoto de Azevedo. Regulação estatal e interesses públicos. São Paulo: Malheiros, 2002.

MEIRELLES, Hely Lopes. Direito administrativo brasileiro. São Paulo: Malheiros, 1996.

MELLO, Celso Antônio Bandeira de. Curso de direito administrativo. 14.ed. São Paulo: Malheiros, 2002.

NEVES, Marcelo. A constitucionalização simbólica. São Paulo: Acadêmica, 1994.

NUSDEO, Fábio. Curso de economia: introdução ao direito econômico. 4.ed. São Paulo: Editora Revista dos Tribunais, 2005.

PIMENTA. Paulo Roberto Lyrio. Contribuições de intervenção no domínio econômico. São Paulo: Dialética, 2002.

SANTI, Eurico Marcos Diniz. As classificações no sistema tributário brasileiro. In: CONGRESSO INTERNACIONAL DE DIREITO TRIBUTÁRIO, 1, 1988, Vitória. Justiça tributária: direitos do fisco e garantias dos contribuintes nos atos da administração e no processo tributário. São Paulo: Max Limonad, 1988.

SANTOS, Boaventura de Souza. A globalização e as ciências sociais. São Paulo: Cortez, 2002.

SILVA, José Afonso da. Curso de direito constitucional positivo. 8.ed. São Paulo: Malheiros, 1992.

SMITH, Adam apud HUGON, Paul. História das doutrinas econômicas. 14 ed. São Paulo: Atlas, 1995. 
SOUZA, Fátima Fernandes Rodrigues de; GARCIA, Patrícia Fernandes de Souza. Nova amplitude do conceito de domínio econômico. In: GRECO, Marco Aurelio (Coord.). Contribuições de intervenção no domínio econômico e figuras afins. São Paulo: Dialética, 2001.

TEUBNER, Gunther. O direito como sistema autopoiético. Tradução de José Engrácia Antunes, Lisboa: Fundação Calouste Gulbenkian, 1993.

VILANOVA, Lourival. Política e Direito: Relação Normativa. Escritos jurídicos e filosóficos. São Paulo: IBET/Axis Mundi, 2003.

Recebido em: 2012-09-20 Aprovado para publicação em: 2012-12-10

Como citar: SANTOS, Alessandro Lucas; KEMPFER, Marlene. Estado contemporâneo e intervenção no domínio econômico. Scientia Iuris, Londrina, v.16, n.2, p.175-198, dez. 2012. DOI: 10.5433/2178-8189.2012v16n2p175. 